\title{
Monte Carlo Simulation as a Research Management Tool
}

Larry J. Douglas

June 1986

To be presented at the 1986 TAPPI Research and Development Conference, September 28 - October 1, 1986, Raleigh, North Carolina

Prepared under Task No. $\mathbf{5 2 5 0 . 2 0}$

FTP No. 616

Solar Energy Research Institute

A Division of Midwest Research Institute

1617 Cole Boulevard

Golden, Colorado 80401-3393

Prepared for the

U.S. Department of Energy Contract No. DE-AC02-83CH10093 


\section{NOTICE}

This report was prepared as an account of work sponsored by the United States Government. Neither the United States nor the United States Department of Energy, nor any of their employees, nor any of their contractors, subcontractors, or their employees, makes any warranty, express or implied, or assumes ariy legal liability or responsibility for the accuracy, completeness or userulness of any information, apparatus, product or process disclosed, or represents that its use would not infringe privately owned rights. 
MONTE CARLO SIMULATION AS A RESEARCH MANAGEMENT. TOOL

Larry J. Douglas, Ph.D. Manager, Strategic Planning Solar Fuels Research Division Solar Energy Research Institute Golden, CO 80401

\section{ABS TRACT}

Monte Carlo simulation provides a research manager with a performance monitoring tool to supplement the standard schedule- and resource-based tools such as the program Evaluation and Review Technique (PERT) and Critical Path Method (CPM). The value of the Monte Carlo simulation in a research environment is that it 1$)$ provides a method for ranking competing processes, 2) couples technical improvements to the process economics, and 3) provides a mechanism to determine the value of research dollars. In this paper the Monte Carlo simulation approach is developed and applied to the evaluation of three competing processes for converting lignocellulosic biomass to ethanol. The technique is shown to be useful for ranking the processes and illustrating the importance of the timeframe of the analysis on the decision process. The results show that acid hydrolysis processes have higher potential for near-term application ( $2-5$ years), while the enzymatic hydrolysis approach has an equal chance to be competitive in the long term (beyond 10 years).

\section{INTRODUCTION}

The managers of research development in government and private sector organizations face the very difficult task of selecting, from among several potential projects, those that most warrant funding from an ever-diminishing research budget. Managers can use a variety of analytical techniques to help evaluate options and finally select the winners from among the candidate processes. This process, often called decision analysis, involves development of criteria related to cost, schedule, and performance. Gantt charts, PERT (Program Evaluation and Review Technique) diagrams, and the CPM (Critical Path Method) analysis are commonly used tools to show schedule and/or cost considerations associated with a project. $(1,2)$ However, they do not provide a quantitative measure of expected performance improvement for the programs under investigation.

The Monte Carlo simulation technique does provide a method to couple performance with the uncertainty in research activity. The basic premise of the Monte Carlo technique is that the uncertainty in a research project can be represented by one or more random normal distribution functions, and that if these uncertainties are coupled to the most sensitive activities in a project, the simulation will yield the most probable results based on the input distributions.

\section{BACKGROUND}

The Solar Energy Research Institute (SERI) is the field manager for the Department of Energy (DOE) program to convert lignocellulosic biomass into ethanol. There are two fundamental approaches to conversion, either through acid hydrolysis of the cellulose to glucose and subsequent fermentation to ethanol or through enzymatic hydrolysis of cellulose and fermentation to ethanol. There are 10 or 12 variations to these basic approaches, and SERI managers must choose the best alternative from among these processes for funding support and further development.

In a recent SERI study titled "Fuel Alcohol Technical and Economic Analysis," (3) a complete evaluation of the numerous process options was conducted. process models were developed on a Lotus 1-2-3 spreadsheet for each of the approaches, and subsequently used to complete parametric and sensitivity analyses for each process. Three processes were the most promising: the plug flow and progressing batch acid hydrolysis processes and the separate hydrolysis and fermentation enzymatic hydrolysis process.

\section{OBJECTIVES}

In this paper we explore the use of Monte Carlo simulation to compare the potential of these three processes for producing ethanol from lignocellulosic biomass. The technical performance improvement for each of the processes will be evaluated by coupling the performance changes to ethanol production costs. As will be seen later, two equally important considerations in ranking the processes are the technical performance improvements to each of these processes important and the time frame in which we evaluate these parametric improvements.

\section{EQUI PMENT}

The use of a Monte Carlo simulation requires a computer model that gives a reasonable representation of the process under study and the development of a large random distribution of input data to run the model. One run might have from 5 to 15 parameters and 250 to 10Ø0 random numbers for each parameter. The large number of iterations (250-1000) involved in a typical Monte Carlo simulation required the use of a main frame computer until the advent of the desktop PC.

With a PC and a spreadsheet program, e.g.., Lotus 1-2-3, it is now possible to complete a Monte Carlo analysis at your desk. The Lotus 
program is particularly useful for doing the simulations because of its ease of modification and debugging, built-in graphics capability, random number generator, and statistical and distribution functions. With a process simulation model developed on a Lotus spreadsheet, it is possible to complete the total Monte Carlo simulation on the same spreadsheet and display the results in graphical format.

\section{GENERAL METHODOLOGY}

The two requirements for generating useful Monte Carlo simulations are a computer model that is a reasonable representation of the process being studied, and a group of random normal distributions that reflect a reasonable expectation value for the selected parameter. The first requirement can be satisfied by evaluating the results of the model over the range of variables being used. The second requires the best judgment of experts in the technology under investigation and their concurrence with the mean values for the parameters and the expected range of each variable.

The general approach to developing and running a Monte Carlo simulation involves four steps :

- Develop a model for the process(es) in question

- Run parametric analyses with the model to determine principal areas of sensitivity

- Develop random normal distributions for each of the sensitive parameters centered about an expectation value
- Run the simulation using the selected, randomized parameters and evaluate the results.

\section{PROCESSES EVALUATED}

Cellulose is converted to ethanol by hydrolyzing the cellulose to glucose and then fermenting the glucose to ethanol. The hydrolysis step can be carried out either by an acidic medium or with enzymes. In this paper we examine two dilute-acid hydrolysis approaches and one enzymatic hydrolysis process and compare them using the Monte Carlo simulation technique.

The Plug Flow Reactor

Figure 1 is the flowsheet for the plug flow acid hydrolysis process. The plug-flow process uses dilute sulfuric acid $(-1 \%)$ at high temperature and pressure, relying on a very short residence time to optimize the yield of cellulose hydrolyzed to glucose. The process uses high-pressure steam to flow a wood slurry through a "pipe" reactor at high speed. At the end of the tube the reaction is quenched; the total residence time is approximately 4 to 5 seconds. The glucose yield ranges from 50\% to $50 \%$ under these conditions. The advantage of this configuration is the concurrent production of furfural from the xylose fraction of the feedstock. The favorable economics of the plug flow process rely heavily on the furfural coproduct selling price.

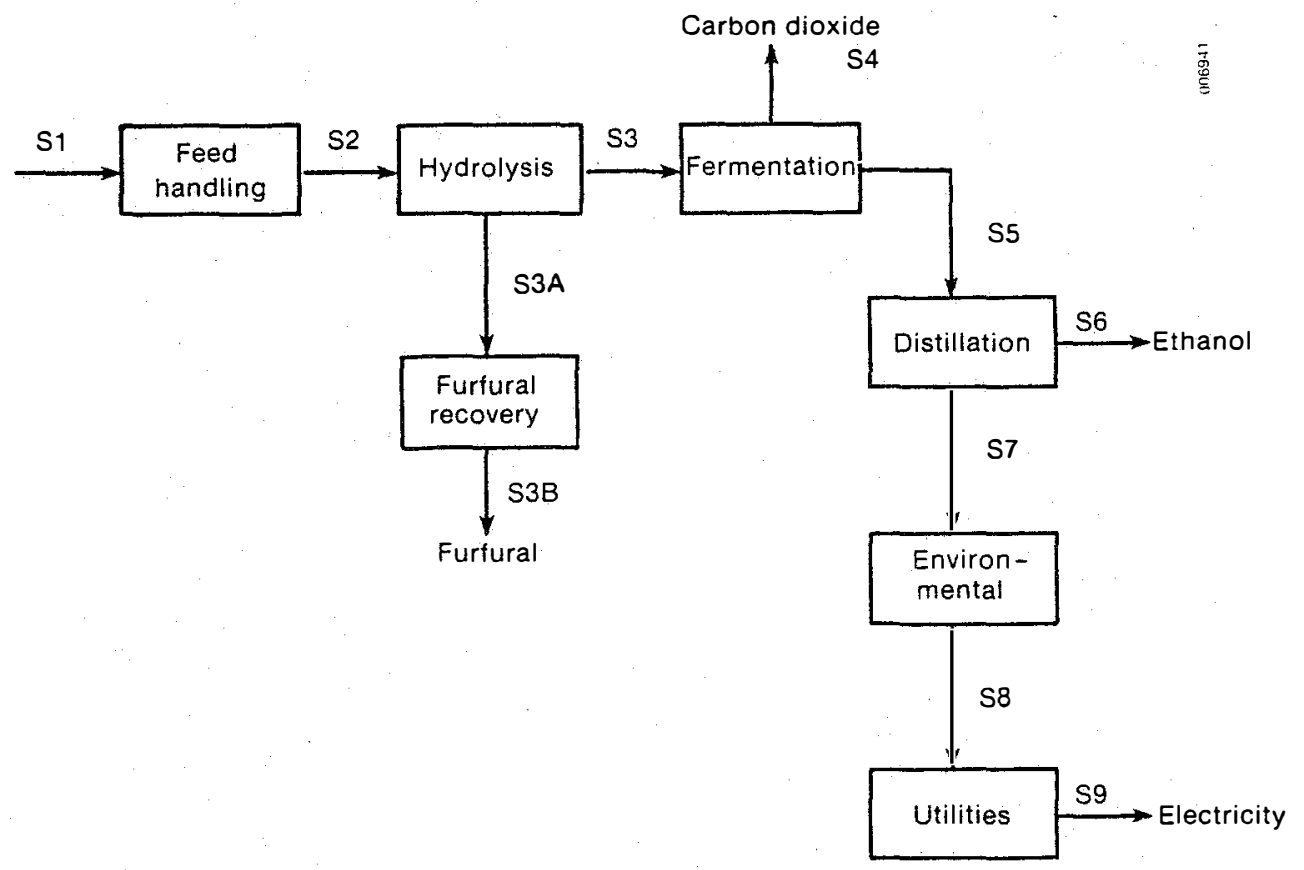

Figure 1. Acid Hydrolysis Flowsheet--Plug-Flow Reactor 
The Progressing Batch Reactor

Figure 2 is the flowsheet for the progressing batch acid hydrolysis process. The progressing batch process uses dilute sulfuric acid in a multireactor adaptation of the percolation-type process, but it simulates countercurrent performance. The process has two temperature zones: one at $150^{\circ} \mathrm{C}$ to selectively remove the hemicellulose portion and a second at $180^{\circ} \mathrm{C}$ to hydrolyze the cellulose. The residence time in this type of process is about two hours. This approach should give higher sugar yields and concentrations than the plug-flow apparatus while also reducing the degradation of both the $\mathrm{C5}$ and $\mathrm{C} 6$ sugars.

\section{Separate Hydrolysis and Fermentation}

Figure 3 is the flowsheet for the separate hydrolysis and fermentation (SHF) process, which is the base system for enzymatic conversion of cellulose to ethanol. The process consists of specialized units to accomplish pretreatment of the feedstock, enzyme production, and hydrolysis of the cellulose to yield glucose followed by a conventional fermentation to produce ethanol. The enzymatic process has the advantage of high yields and cleaner process streams than the acid processes, but suffers from low rates of hydrolysis and enzyme production and, at present, a prohibitively high enzyme production cost.

\section{MODELS}

The models used to complete the Monte Carlo simulations were developed on a Lotus spreadsheet and were based on the models prepared in conjunction with the above-mentioned Fuel
Alcohol Technology and Economic study. The design basis for all the models was the state-of-the-art cellulose-to-ethanol plant designed by Badger Engineers (4) in 1984. The base-case plant produces $25, \overline{0} 00,000$ gallons of ethanol per year from a feedstock of mixed hardwoods. To assure the comparability of the results, all the designs were the same except the pretreatment and hydrolysis sections, which were specific to the individual processes.

From the process designs and material balances, the cost of producing ethanol is calculated. The capital costs were estimated using the ICARUS'. computer-aided cost estimating program. The base-case processes were developed on a Lotus 1-2-3 spreadsheet, which allowed easy parametric recalculation of the material balance. With the material balance calculated it is easy to use the spreadsheet models to calculate the electrical and thermal energy requirements of the process, the overall plant energy balance, and the plant capital cost. This information provides the basis for calculating the cost of raw materials, utilities, labor, overhead and maintenance, by-product credits, annualized capital charges, and the selling price of ethanol. These models also allow rapid calculation of sensitivities and the parametric analyses necessary to identify the parameters for inputs into the Monte Carlo simulations.

\section{RESULTS AND DISCUSSION}

With a well-developed model we can develop the input distributions for running the simulation. As an example, the economic performance of the progressing batch process was found to be very sensitive to the liquid residence time in the reactor. A consensus

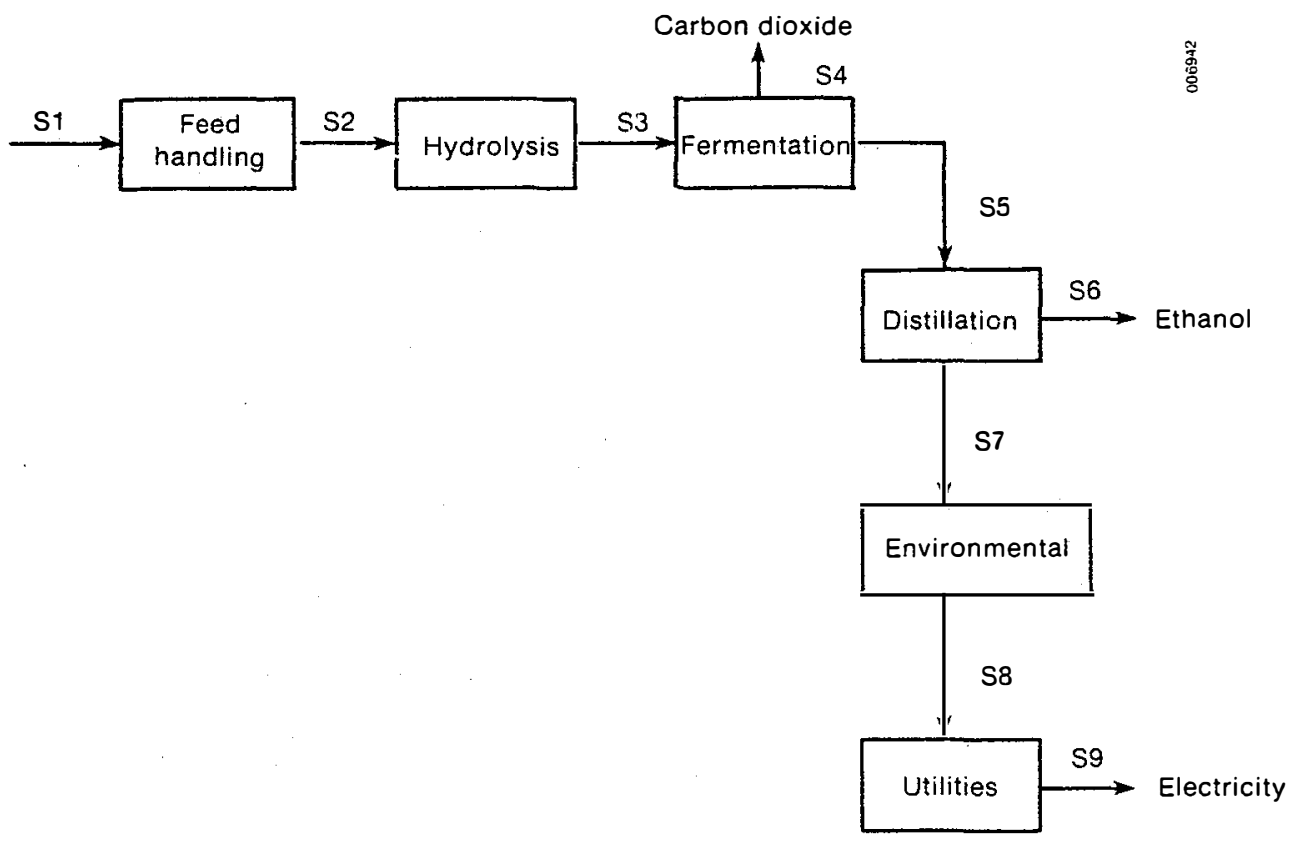

Figure 2. Acid Hydrolysis Flowsheet--Progressing Batch Reactor 


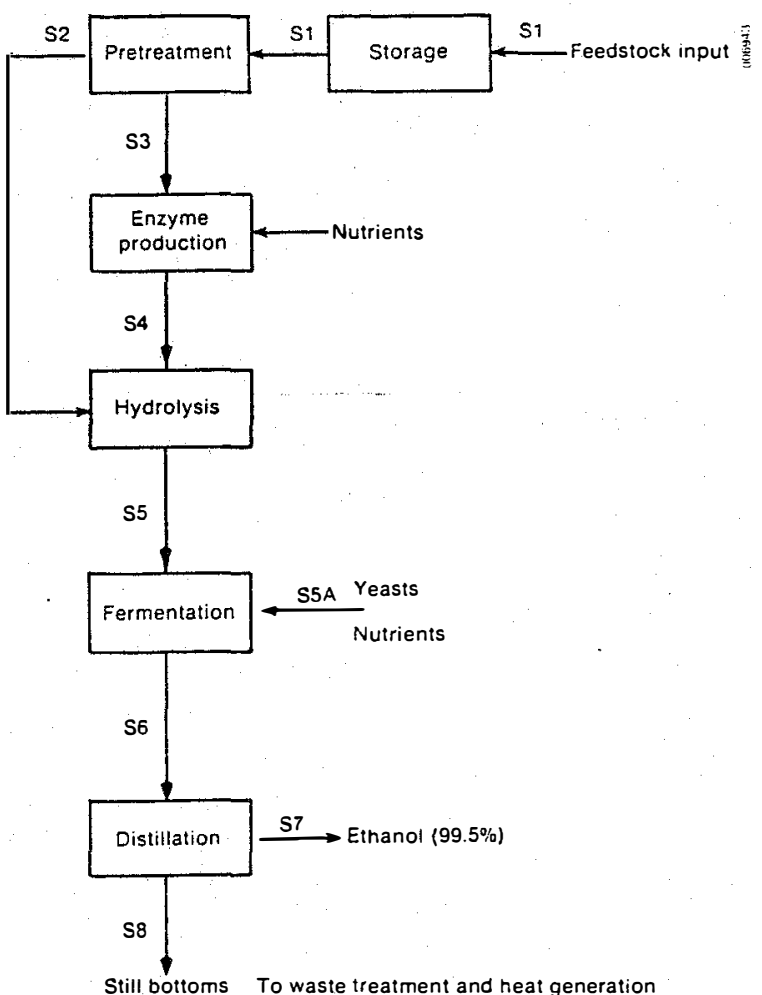

Figure 3. Separate Hydrolysis and Fermentation Flowsheet

of experts in acid hydrolysis suggested a normal distribution to be generated that had a mean (expectation) value of 45 minutes and sigma (the standard deviation) of 10. This distribution contained 250 points and was used to run a Monte Carlo simulation using the Lotus 1-2-3 model for the progressing batch process, resulting in the output shown in Figure 4. Figure $4 a$ shows the output distribution histogram for the selling price of ethanol; this curve was integrated to yield the cumulative probability curve shown in Figure $4 \mathrm{~b} .(5)$ The 0.5 value on the probability curve corresponds to the expected selling price for ethanol resulting from this simulation.

The simulations discussed in the remainder of the paper were run using multiple variables. The variables were chosen based on the results of sensitivity analyses completed for each of the processes.

The economic performance of the plug flow dilute acid hydrolysis process was found to be very sensitive to the percent solids entering the reactor feed pump and to the assigned selling price for the furfural coproduct. The plug flow system was configured to operate using a 10 o solids slurry produced ethanol at a selling price of $\$ 2.04 /$ gallon, while a $20 \%$ solids slurry system gave ethanol at about $\$ 1.29 / \mathrm{gallon}$. When the coproduct furfural selling price was set to zero the ethanol selling price was $\$ 1.99 / g a l l o n$. At
Population distribution
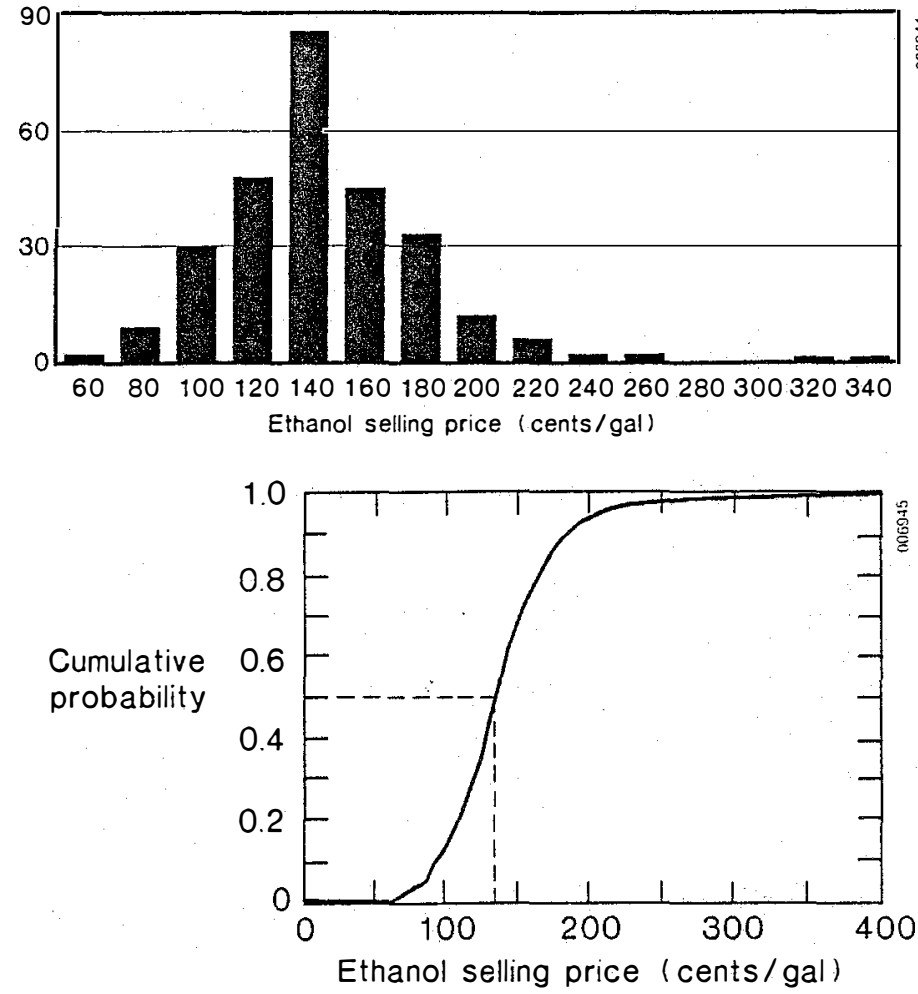

Figure 4. Progressing Batch Acid Process 250 Point Monte Carlo Simulation

\$0.12/pound for furfural credit the ethanol selling price dropped to $\$ 1.29 / g a l l o n$. At $250^{\circ} \mathrm{C}$ the price for ethanol increased to $\$ 1.38 / g a l l o n$ and at $280^{\circ} \mathrm{C}$ the selling price dropped to $\$ 1.22 /$ gallon. A 0.58 acid concentration in the reactor increased the selling price of ethanol to $\$ 1.32 / \mathrm{gallon}$, and a 18 acid concentration in the reactor resulted in an ethanol selling price of $\$ 1.29 / \mathrm{gallon}$ (which is the base case).

- The plug flow simulations were run using four variables; percent solids in the reactor, by-product credit for furfural, temperature, and acid concentration.

The economic performance of the progressing batch acid hydrolysis process was also found to be sensitive to the percent solids in the reactor; e.g., at $10 \%$ solids loading in the reactor the selling price of the product ethanol was $\$ 2.02 / \mathrm{gallon}$, and at 188 solids produces an ethanol selling price of $\$ 1.41 / g a l l o n$. The operating temperature of the prehydrolysis and the hydrolysis reactors was found to impact the economics. With the prehydrolysis temperature increased from $150^{\circ}$ to $165^{\circ} \mathrm{C}$ the ethanol selling price rose to $\$ 1.52 / g a l l o n$. With the hydrolysis temperature lowered from $189^{\circ}$ to $165^{\circ} \mathrm{C}$ the selling price of ethanol increased to $\$ 2.83 / \mathrm{gallon}$. Reducing the 1 iquid residence time from 45 to 25 minutes increased the ethanol selling price to $\$ 1.74 / g a l l o n$. The addition of $x y-$ lose fermentation to ethanol to the process 
reduced the selling price of the product ethanol to $\$ 0.99 / \mathrm{gallon}$. The base-case process configuration produces ethanol selling for $\$ 1.41 /$ gallon.

- The progressing batch simulations were run using five variables: reactor packing density, prehydrolysis temperature, hydrolysis temperature in main reactor, liquid residence time, and xylose fermentation to ethanol.

The economic performance of the separate hydrolysis and fermentation enzymatic process was found to be particularly sensitive to percent solids in the hydrolysis reactor, enzyme loading in the hydrolysis step, hydrolysis time, hydrolysis yield, enzyme productivity, xylose conversion to ethanol, and lignin coproduct credit. The base-case process produced ethanol at a selling price of $\$ 2.60 / g a l l o n$.

Increasing the solids loading in the hydrolysis reactor from $10 \%$ to $20 \%$ reduced the selling price of ethanol to $\$ 2.12 /$ gallon. Reducing the enzyme loading from $20 \mathrm{IU} / \mathrm{gram}$ of solids to 7.5 IU/gram reduced the selling price of ethanol to $\$ 2.10 / g a l l o n$. Reducing the hydrolysis time from 72 to 24 hours lowered the ethanol price to $\$ 2.29 / \mathrm{gallon}$. Including xylose fermentation to ethanol lowered the selling price of ethanol to $\$ 1.76 / g a l l o n$. Increasing the hydrolysis yield to 958 reduced the price of ethanol to $\$ 2.22 / g a l l o n$. An $8 x$ increase in the rate of enzyme production reduces the selling price of ethanol to $\$ 2.23 / \mathrm{gallon}$. Separating the lignin fraction of the feedstock and realizing a net value of $\$ 0.07 /$ pound coproduct credit reduces the ethanol selling price to $\$ 1.91 /$ gallon.

- The separate hydrolysis and fermentation simulations were run with seven variables: percent solids in the hydrolysis reactor, enzyme loading, hydrolysis time, hydrolysis yield, xylose fermentation, enzyme productivity, and lignin by-product credit.

Figure 5 shows a comparison of the output from Monte Carlo simulations for all three processes in 1980, Figure 6 shows the same processes in 1985, and Figure 7 shows the projected comparison in 1990.

In 1980 there was no progressing batch process and little information was available on the then newly developed plug flow process. For the purposes of this report, the progressing batch process for 1980 was simulated using the standard percolation process as the basis. The difference in the expectation selling price for the two acid processes in 1980 was minimal; both would sell for about $\$ 2.35 / g a l l o n$. In the same time frame the expected selling price for ethanol from the SHF process was about $\$ 6.80 / \mathrm{gallon}$.

The 1985 results shown in Figure 6 demonst ate the improvement in the expectation

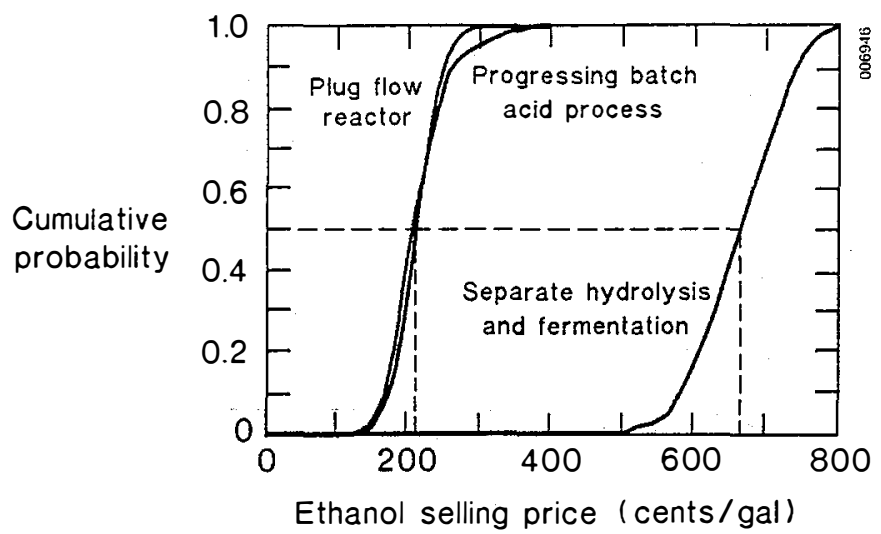

Figure 5. Monte Carlo Simulation, 1980

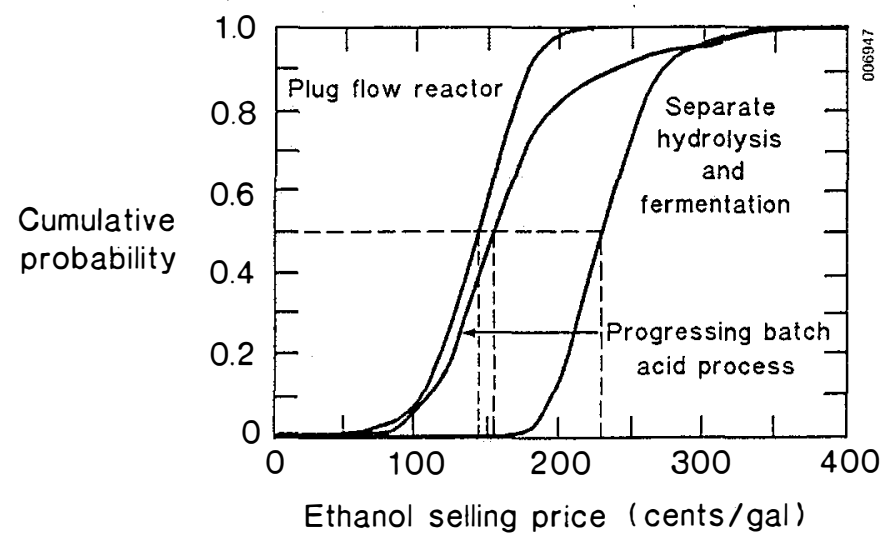

Figure 6. Monte Carlo Simulation, 1985

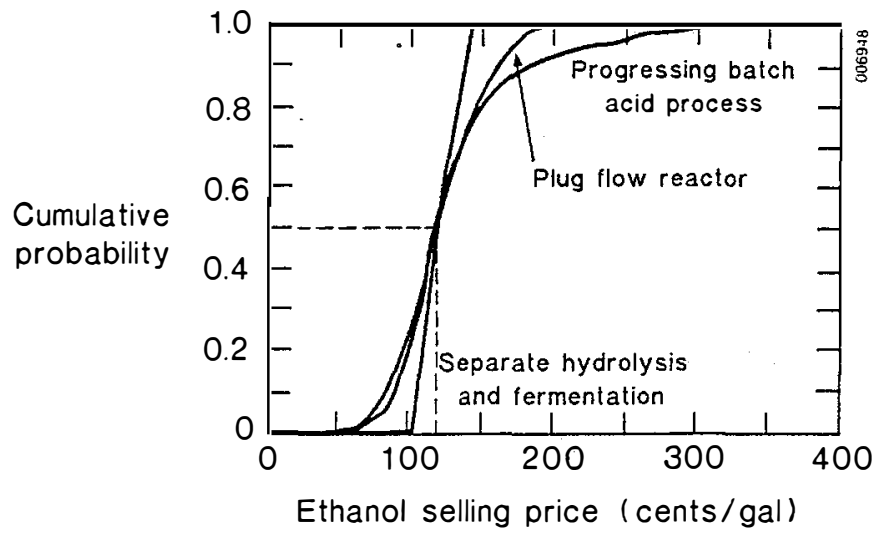

Figure 7. Monte Carlo Simulation, 1990

values for all three processes. The plug flow process now is at about $\$ 1.35 /$ gallon and the progressing batch process at about $\$ 1.50 / g a l l o n$. This is a significant reduction compared to the 1980 values. The SHF process shows even a more dramatic improvement, dropping from $\$ 6.80 / \mathrm{gallon}$ to about $\$ 2.50 /$ gallon.

By 1990 all three processes have about the same expectation value for ethanol selling price, and any difference among the processes 
will have to be evaluated outside the parameters used to complete the Monte Carlo simulations.

\section{CONCLUSIONS}

The Monte Carlo simulation technique offers the research manager a tool to monitor performance improvement and supplement the schedule and cost data generated by conventional management tools such as PERT and CPM. The value of the Monte Carlo simulation in a research environment is that it 1) provides a method for ranking competing processes, 2) couples technical improvements to the process economics, and 3) provides a mechanism to determine the value of research dollars.

The processes discussed above illustrate the use of Monte Carlo simulation that produces a result that will allow a manager to rank ethanol processes according to their ability to produce ethanol at a price competitive with alternate approaches. In addition, if the time horizon for implementation of a new process is important, the ability to have a ranking system with time attached becomes important. In the cases above, if a plant is to be constructed in the next two or three years then one of the acid hydrolysis processes would be preferred; however, if the new plant was to start after 1990 all the processes are on equal footing and other criteria would be used to differentiate among them.

Figure 8 shows the impact of changing the percent solids entering the plug flow reactor from 128 to 18\%. This single change in technical performance of the hydrolysis reactor reduces the selling price of ethanol from $\$ 1.90 / g a l l o n$ to about $\$ 1.45 / \mathrm{gallon}$. This type of analysis also helps determine the direction of future research and engineering activity. The development of a hydrolysis approach and associated reactor hardware that can handle $20 \%$ solids is our current goal for the plug flow acid hydrolysis process. The sensitivity of the process economics to this parameter is so dominating that if this ob-

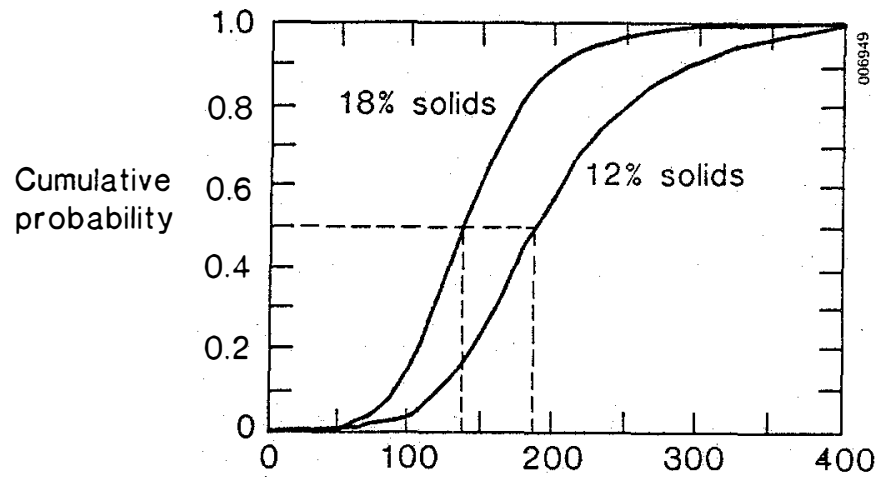

Ethanol selling price (cents/gal)

Figure 8. Plug Flow Reactor 250 Point Monte Carlo Simulation jective is not met the process will cease to be competitive with the other approaches and dropped from further consideration.

In the progressing batch and separate hydrolysis and fermentation processes the economics could be greatly improved with the addition of xylose fermentation to ethanol. This step would increase the ethanol yield by as much as 508 to 708 . Figure 9 shows the impact of xylose conversion on the economics of ethanol production for the progressing batch process. If we assign a dollar figure to each of the conversion yields and assume that this curve is generated for the year 1990, then with no funding for research to improve $x y-$ lose fermentation we would stay at our present position of no ethanol from xylose. Each of the higher yields represents the estimated improvement in xylose fermentation projected by technical experts based on three different budgeting scenarios: $\$ 75,000 /$ year, $\$ 150,000 /$ year, and $\$ 300,000 /$ year for five years. The argument is very convincing that the resulting xylose conversion yield and impact of process economics are directly coupled to the funding level over the five years of research.

\section{REFERENCES}

1. Antunes, J., and Klopp, G.., "A Method for Performance Risk Analysis," Model Simulation Processes, løth Annual Pittsburgh Conference, 1979.

2. Muglia, V. O., "REM Management using Risk Analysis," Proceedings, 1976 Annual Reliability and Maintainability Symposium, Las Vegas, Nev., pp. 230-233.

3. Solar Energy Research Institute, Fuel Alcohol Technical and Economic EvaluaEion, Draft, February 1986, Golden, Colo.

4. Badger Engineers, Inc., "Economic Feasibility of an Acid-Based Ethanol Plant," Subcontract to Solar Energy Research Institute, Badger Engineers, Inc., One Broadway, Cambridge, MA 02142 .

5. Bury, K. V., Statistical Models in Applied Science, Chapter 2, John Wiley and Sons, 1975.

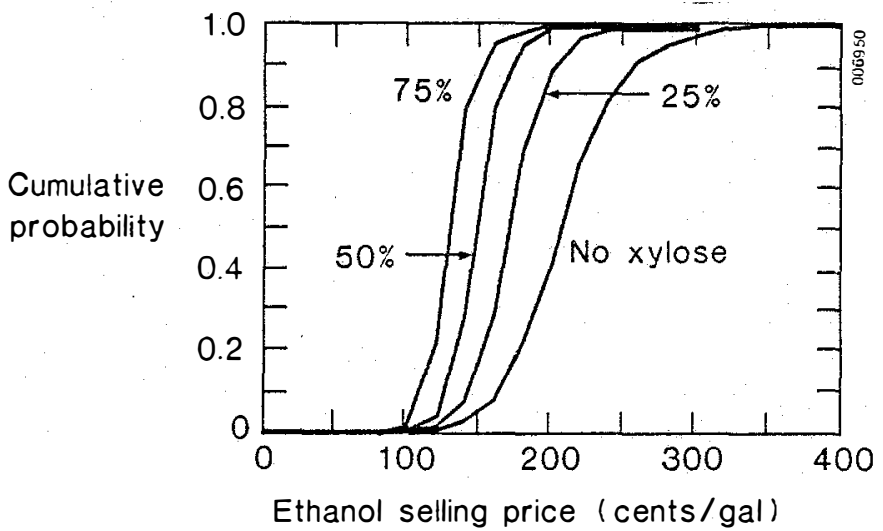

Figure 9. Xylose Fermentation Impact in Progressing Batch Reactor 